\title{
Ebola virus disease: where are we now and where do we go?
}

\author{
Colin S Brown, ${ }^{1,2}$ Ian M Cropley ${ }^{1}$
}

Despite its vivid place in the popular imagination, conjuring up images of germ warfare and Hollywood blockbusters, Ebola has previously affected a relatively small number of people. Prior to 2014, approximately 2400 people were infected, with just over 1500 deaths in the four decades since its 1976 discovery in Zaire and Sudan. ${ }^{1}$ Smaller outbreaks occurred in the late 1970s, with sporadic, larger ones each numbering under 500 cases seen in the Democratic Republic of Congo (Zaire) and Uganda in the 1990s, 2000s and early 2010s. Ebola virus disease (EVD) was therefore largely thought to be an exotic, tropical disease confined to self-limiting outbreaks in rural central Africa. It was considered a terrifying but unsuccessful virus, killing off its hosts too quickly to transmit it to many others. It felt remote. The 2014 outbreak has forever changed those perceptions.

In early March 2014, Guinea announced that an outbreak of unexplained illness with high mortality around Guéckédou and Macenta, near the country's south-western border with Sierra Leone and Liberia, was due to EVD. Cases soon emerged in northern Liberia and were seen in eastern Sierra Leone by the end of May. This was to be expected, given that the early epicentre of the outbreak mapped exactly on to the homelands of the Kissi people, whose shared culture is blind to national borders. Nigeria and Senegal have since seen imported cases, further exacerbating the regional crisis.

The West African virus has been confirmed to be part of the Zaire ebolavirus (EBOV) lineage, with a probable separation around 2004 from the central African virus. Introduction into the West African population was from one animal-to-human transmission, probably a fruit bat. ${ }^{2}$ This single introduction into the human population has been traced to a Guinean child infected in December 2013, although not recognised until March 2014. ${ }^{3}$ Research suggests that Ebola may have been present for many years in the affected region. ${ }^{4}$ Why this is

\footnotetext{
${ }^{1}$ Royal Free London NHS Foundation Trust, London, UK; ${ }^{2}$ King's Sierra Leone Partnership, London, UK

Correspondence to Dr Colin S Brown, Royal Free Hospital, Pond Street, London NW3 2QG, UK; colinbrown1@nhs.net
}

the first recognised outbreak is unclear, although, as with most EVD outbreaks, early symptoms are non-specific and closely mimic many diseases of infectious aetiology -malaria, enteric pathogens, typhoid, severe sepsis.

Diagnosis is therefore difficult to achieve by symptom recognition or clinical acumen alone, particularly in countries where even basic microbiological services are limited. Efforts are further hampered by patient reluctance to present for testing or offer complete contact details of ill family members, often remaining at home to be cared for by relatives. This is understandable-if loved ones are sent to treatment centres, there is a high likelihood they will never be seen again. Helping those affected to access care is of paramount importance, particularly in a context where national and international efforts have been met with resistance.

Health systems, already strained from decades of conflict, have been overwhelmed. Many long-term partners from the international community have withdrawn staff, exacerbating the challenges. Each new suspected case brings an exponential increase in resources required for testing, isolation and contact tracing. Now that the outbreak has spread to nearly every region of the most affected countries (Sierra Leone, Guinea and Liberia), risk assessment and differentiation from common pathogens becomes increasingly difficult by immediately rendering obsolete newly established protocols for who to isolate and who to test. This can be seen in figure 1 by comparing regions affected in mid-June with the end of September, where geographic risk assessment was initially possible in Sierra Leone and Liberia but is no longer the case. The collapse of generic healthcare infrastructure-antenatal and maternity care, management of tuberculosis, HIV and chronic illness, and surgical emergencies-is a tragedy that compounds risk assessment.

Local transmission has been propelled by lack of basic infection control measures -gloves, gowns, running water, bleach. These are fundamental issues, which should be easily solved, but remain key drivers in many areas. Rapid detection and treatment of cases with appropriate community discussion and engagement to encourage early presentation was absent in early stages. Appropriate and well-staffed facilities for isolation and treatment, and adequate public health infrastructure for contact tracing and coordination, are overdue and urgently needed.

The likelihood of increased outbreaks due to human and virological factors-for example, increased travel and divergent strains-is well known, ${ }^{5}$ so what makes this outbreak so different from those seen before? Answers include a single ethnic group geographically placed across multiple countries, urbanisation, denser population concentrations with improved infrastructure, and better access to hubs of national and international travel $^{6}$-all coupled with inertia from the international community. What is clear is that, in addition to the immediate human tragedy, the economic consequences are devastating: Sierra Leone, one of the poorest countries in the world, saw economic growth of $15 \%$ in 2012 and $13 \%$ in 2013, with an anticipated projection of $14 \%$ in $2014 .^{7}$ This has been severely affected by losses in mining and agriculture and loss of business through restrictions of international travel.

The first British national infected in the current outbreak setting was repatriated in August 2014 from Sierra Leone-he was discharged in early September from the Royal Free Hospital, although it remains likely that London may have further imported or repatriated cases. London is home to a large West African diaspora community, with over 17000 Sierra Leoneans in 2001, and is among the most globally connected of the major cities of the world. The USA has recently seen the first imported case outside of West Africa, and modelling based on regional flight patterns has suggested that the UK is one of the three countries most likely to see importation of cases after Ghana and Gambia. ${ }^{8}$ Germany, France, Spain, and the USA have also treated infected patients evacuated from West Africa. The USA and Spain have seen further transmission among medical personnel. Other European countries have large diaspora communities of Liberians and Guineans. Onward spread is a concern shared globally.

Several novel therapeutic treatment options are on the horizon, but those that have been developed have not been rigorously tested with human EVD, and, even if development progresses rapidly, they are unlikely to change the course of this epidemic. ${ }^{9}$ Vaccine trials have started, but remain in the early stages, although re-exposure vaccination has proved effective in preventing infection in macaques. ${ }^{10}$ Current vaccine studies are only in phase 

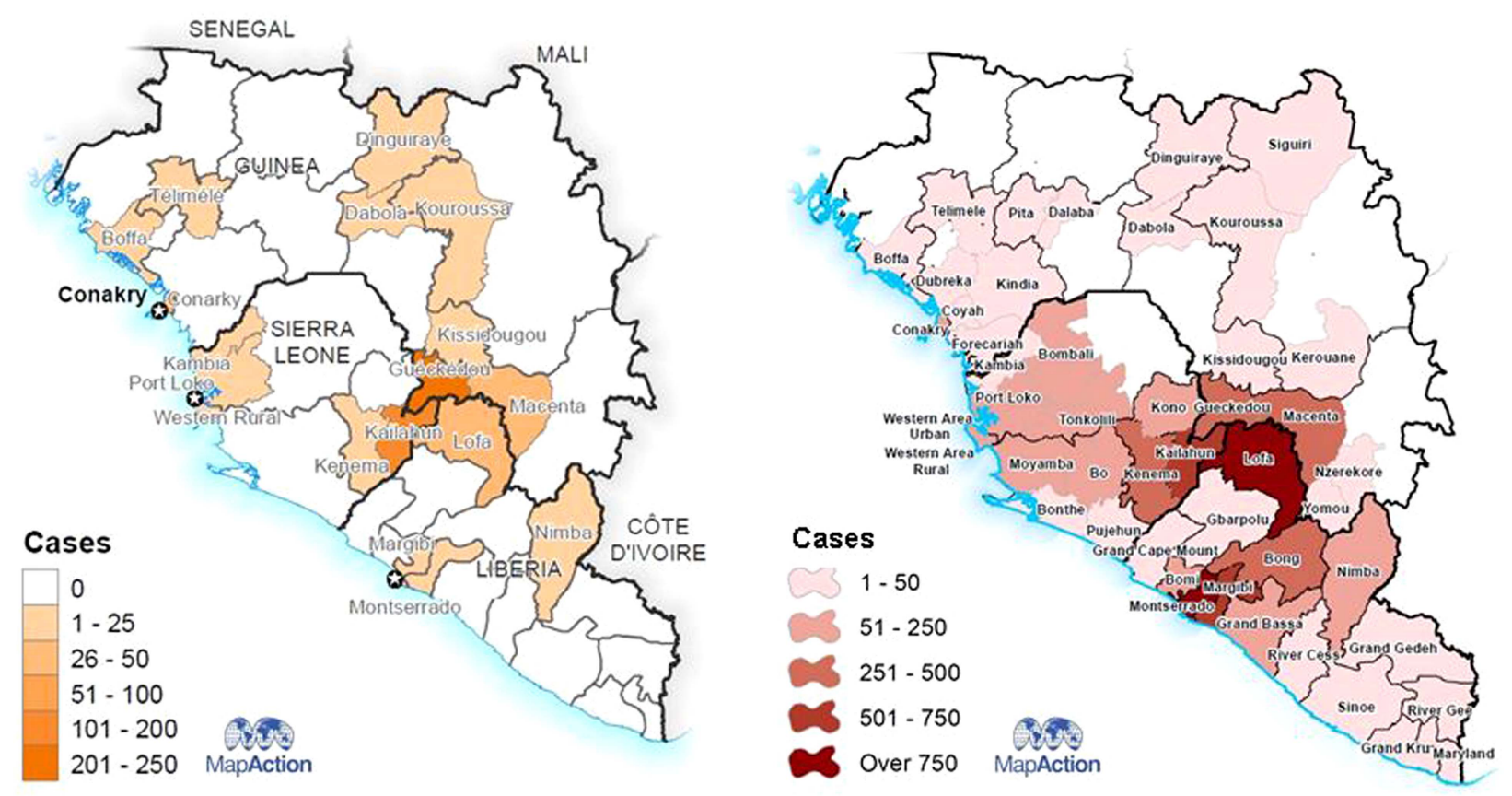

Data Sources: GADM, WHO, UNMIL, OCHAA, ACAPSBriefing Note

Map produced by MapAction and ACAPS

Figure 1 Reported cumulative case numbers as of 22 June and 26 September 2014.

I trials using only healthy volunteers. Laudable calls for clinical trials in affected countries are challenging given the obstacles to basic care, but there is a moral imperative to explore treatments that could save lives on the ground. Simple containment measures long known to be effective remain the cornerstone of control, but must be applied consistently and require human and material resources and engagement of local communities.

On 7 August 2014, the WHO declared the West African EVD outbreak a 'Public Health Emergency of International Concern'; this was welcome and long overdue given the unprecedented onward regional and international spread and the very limited global response to date. The Response Roadmap published on 28 August detailed a clear pathway, with sustained and committed effort from technical experts, national public health bodies, and donor and funding agencies required. ${ }^{11}$ It should and must galvanise the will of the international community to cooperation and action. Projections as of September 2014 show that, with exponential growth and without immediate international investment in human resourcing, cumulative infections could rise to 20000 by November 2014 and 1400000 by January 2015. ${ }^{12} 13$ Currently, patients are being sent home-no beds equals no care equals no chance for control efforts.
The greatest challenge remains in human resourcing-the WHO calculated some 13000 national personnel were required to engage in logistics, public awareness, contact tracing, surveillance, and case management efforts at the end of August 2014. ${ }^{11}$ Delays in interventions in the face of exponential spread are difficult to comprehend, and by the time of delivery are already out of date. Where staffing levels will come from remains unanswered, and it is clear the countries affected do not have the levels of trained staff required. Global resilience, preparedness and response have been criticised, but what matters now is control; this is an international imperative, and the challenges facing West Africa must be met with worldwide support. There has been a call for British volunteers to have flexibility to support relief efforts, ${ }^{14}$ in keeping with the long-stated aims of using NHS staff to benefit international health and development efforts. ${ }^{15}$ Now is the time to demonstrate our commitment to these goals; UK-Med (http://uk-med. humanities.manchester.ac.uk/) have led these efforts and we must respond with will and commitment. Immediate action represents the only hope of stopping this tragedy and its present and future impact.

Competing interests None.
Provenance and peer review Commissioned; internally peer reviewed.

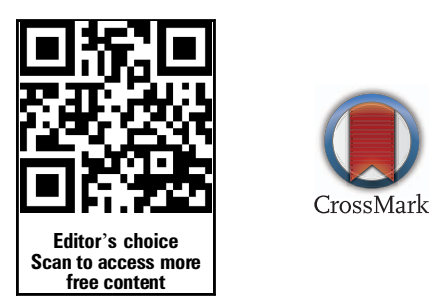

To cite Brown CS, Cropley IM. Postgrad Med J 2014;90:610-612.

Received 3 October 2014

Accepted 3 October 2014

Postgrad Med J 2014;90:610-612.

doi:10.1136/postgradmedj-2014-133068

\section{REFERENCES}

1 Centers for Disease Control and Prevention. Outbreaks Chronology: Ebola Virus disease. 2014. http://www.cdc.gov/vhf/ebola/resources/ outbreak-table.html (accessed 6 Sept 2014).

2 Gire SK, Goba A, Andersen KG, et al. Genomic surveillance elucidates Ebola virus origin and transmission during the 2014 outbreak. Science 2014;345:1369-72.

3 Baize S, Pannetier D, Oestereich L, et al. Emergence of Zaire ebola virus disease in Guineapreliminary report. N Engl J Med 2014;371:1418-25.

4 Schoepp RJ, Rossi CA, Khan SH, et al. Undiagnosed acute viral febrile illnesses, Sierra Leone. Emerg Infect Dis 2014;20:1176-82.

5 Changula K, Kajihara M, Mweene AS, et al. Ebola and Marburg virus diseases in Africa: increased risk of outbreaks in previously unaffected areas? Microbiol Immunol 2014;58:483-91. 


\section{Editorial}

6 Bannister B. Viral haemorrhagic fevers imported into non-endemic countries: risk assessment and management. Br Med Bull 2010;95: 193-225.

7 World Bank. Sierra Leone Overview (cited 6 September 2014). http://www.worldbank.org/en/ country/sierraleone/overview

8 Gomes MFC, Pastore y Piontti A, Rossi L, et al. Assessing the international spreading risk associated with the 2014 West African Ebola outbreak. PLoS Curr. Published: 2 Sep 2014. doi: 10.1371/currents outbreaks.cd818f63d40e24aef769dda7df9e0da5.
9 Qiu X, Wong G, Audet J, et al. Reversion of advanced Ebola virus disease in nonhuman primates with ZMapp. Nature 2014;514:47-53.

10 Stanley DA, Honko AN, Asiedu C, et al. Chimpanzee adenovirus vaccine generates acute and durable protective immunity against ebolavirus challenge. Nat Med 2014;20:1126-9.

11 World Health Organization. Ebola response roadmap Geneva: WHO, 2014.

12 Meltzer Ml, Atkins CY, Santibanez S, et al. Estimating the future number of cases in the Ebola epidemic — Liberia and Sierra Leone, 2014-
2015. MMWR Surveill Summ 2014:63:

$1-14$.

13 WHO Ebola Response Team. Ebola virus disease in West Africa-the first 9 months of the epidemic and forward projections. N Engl J Med. Published Online First: 22 Sep 2014. doi:10.1056/NEJMoa1411100

14 Houlihan C, Behrens R, Moore D. NHS contribution to the Ebola epidemic. BMJ 2014;349:95079.

15 Department of Health. Engaging in global health: information for health sector workers and employers about the opportunities and benefits of volunteering abroad. London: Department of Health, 2014. 